\title{
PENGEMBANGAN MEDIA REALIA UNTUK MENINGKATKAN HASIL BELAJAR MATEMATIKA
}

\author{
Ninik Kuswariyanti \\ SD Negeri Kedungcaluk I, Kabupaten Probolinggo \\ ninikkuswariyanti056@gmail.com
}

\begin{abstract}
Abstrak
Media realia merupakan suatu benda nyata yang dapat digunakan sebagai alat bantu dalam kegiatan pembelajaran. Media realia yang digunakan bersifat bebas, boleh berupa sedotan, manik-manik, lego, atau benda apa saja yang dimiliki oleh siswa untuk dapat mendukung kegiatan belajar. Tujuan penelitian ini adalah untuk meningkatkan hasil belajar siswa pada pelajaran matematika pada materi pembagian. Metode penelitian yang digunakan adalah Penelitian Tindakan Kelas pada siswa kelas 2 SD Negeri Kedungcaluk 1 Kecamatan Krejengan Kabupaten Probolinggo pada semester genap tahun pelajaran $2019 / 2020$. Hasil penelitian menunjukkan bahwa nilai tes hasil belajar siswa dari pra siklus ke siklus 1 lalu siklus 2 meningkat secara signifikan, yaitu sebesar $11,68 \%$ dari rata-rata nilai tes pada pra siklus ke siklus 1, kemudian terdapat kenaikan 6,44\% dari siklus 1 ke siklus 2. Selain meningkatkan hasil belajar, media realia juga menumbuhkan semangat dan motivasi belajar siswa serta melatih kemandirian siswa untuk bernalar dengan baik dalam menemukan sendiri algoritma pembagian tradisional.
\end{abstract}

Kata kunci: Media Realia, Hasil Belajar, Matematika, Pembagian

\begin{abstract}
Realia media is a real object that can be used as a tool in learning activities. The realia media used are free, can be in the form of straws, beads, legos, or whatever objects are owned by students to support learning activities. The purpose of this study was to improve student learning outcomes in mathematics in the distribution material. The research method used was Classroom Action Research in grade 2 SD Negeri Kedungcaluk 1, Krejengan District, Probolinggo Regency in the even semester of the 2019/2020 school year. The results showed that the test scores of student learning outcomes from pre-cycle to cycle 1 then cycle 2 increased significantly, namely $11.68 \%$ from the average test value in pre-cycle to cycle 1, then there was an increase of $6.44 \%$ from the cycle. 1 to cycle 2. In addition to improving learning outcomes, media realia also fosters enthusiasm and motivation for student learning and trains students to reason well independently in finding their own traditional division algorithms.
\end{abstract}

Keywords: Realia Media, Learning Outcomes, Mathematics, Fraction 


\section{PENDAHULUAN}

Matematika merupakan ilmu pengetahuan yang berkembang pesat dan menjadi suatu ilmu dasar dalam kehidupan manusia (Kamarullah, 2017). Matematika merupakan sebuah ilmu dasar yang selalu digunakan dalam kegiatan sehari-hari. Misalnya dalam melakukan jual beli, mengetahui luas suatu wilayah, memperkirakan jarak tempuh, atau juga melakukan penalaran dalam menghadapi suatu peristiwa. Matematika tidak hanya sekadar menghitung menggunakan rumus, melainkan sudah merupakan kebutuhan dalam hidup manusia. Disadari atau tidak, manusia akan selalu menggunakan matematika dalam kehidupan sehari-hari.

Berdasarkan survey Programme of International Student Assesment (PISA) pada tahun 2015, kemampuan matematika siswa Indonesia berada dalam urutan ke 63 dari total 69 negara (Pratiwi, 2019). Pada era revolusi industry 4.0 seperti sekarang, setiap negara dituntut agar bisa menyesuaikan diri mengikuti perkembangan matematika. Matematika menjadi penting untuk diajarkan sedini mungkin demi mempersiapkan generasi yang siap menghadapi tantangan zaman.

Melalui pengamatan di kelas 2 SD Negeri Kedungcaluk I Kecamatan Krejengan Kabupaten Probolinggo, hasil belajar matematika siswa belum optimal. Terdapat 25\% siswa yang memiliki nilai di bawah Kriteria Ketuntasan Minimal (KKM), siswa kesulitan menjawab pertanyaan, serta belum memahami informasi yang disampaikan guru.

Siswa kelas 2 SD memiliki pola berpikir peralihan dari konkret menuju abstrak (Suwardi, Firmiana, \& Rohayati, 2014). Mereka memerlukan suatu bentuk konkret untuk agar bisa mempelajari matematika. Mereka lebih mudah belajar sesuatu yang dialami dalam kesehariannya dan bersifat nyata. Misalnya saja dalam menghitung $8: 2$. Untuk menjelaskan kepada siswa kelas 2 SD, bagaimana melakukan perhitungan tersebut, maka diperlukan suatu media yang bersifat nyata. Suatu hal yang konkret sangat diperlukan agar bisa menanamkan konsep pembagian dengan tepat. Penanaman konsep ini sangat penting dilakukan. Matematika sebagai ilmu pasti yang memiliki logika berhitung yang hendaknya juga dipelajari dengan menggunakan penalaran yang tepat, bukan penghafalan teori belaka tanpa suatu logika (Cipta, 2019).

Mengikuti pola berpikir siswa kelas 2 SD tersebut, maka diperlukan suatu benda nyata yang dihadirkan dalam kegiatan pembelajaran. Benda nyata yang bisa digunakan dapat berupa kerikil, lego dengan bentuk sejenis, alat tulis, atau apa pun. Benda nyata inilah yang disebut media realia. (Sari, 2020) menyebutkan bahwa media realia adalah suatu alat yang digunakan dalam pembelajaran dengan melibatkan seluruh indra siswa, yaitu Prismatika: Jurnal Pendidikan dan Riset Matematika Vol. 3 No. 2 (2021) p-ISSN: 2654-6140, e-ISSN: 2656-4181 http://ejurnal.budiutomomalang.ac.id/index.php/prismatika 
penglihatan, pendengaran, peraba, serta dapat menggerakkan hati siswa untuk belajar dengan semangat. Media realia bersifat nyata dan digunakan sebagai bahan ajar (Sugiharti, 2018) dengan ciri merupakan benda asli yang dalam keadaan untuh, dapat dioperasikan, serta dapat dikenali sebagaimana wujud aslinya (Ardini, Ibrahim, Zubaidi, \& Syahputra, 2019). Dengan demikian, media realia tersebut harus bersifat menarik. Mulai dari warnanya yang cerah dan mencolok hingga bentuknya yang lucu untuk siswa kelas 2 SD.

Melalui media realia, diharapkan siswa dapat memahami pembagian dengan lebih baik. Belajar matematika menjadi pembelajaran yang menyenangkan dan memberikan pemahaman yang optimal bagi siswa karena mereka telah melihat secara langsung dan menggunakannya dalam kegiatan belajar. Dengan demikian, berdasarkan pembahasan tersebut, maka pembelajaran marematika melalui media realia diharapkan dapat meningkatkan hasil belajar matematika pada siswa kelas 2 SD Negeri Kedungcaluk 1, Kecamatan Krejengan, Kabupaten Probolinggo dengan mengoptimalkan kompetensi belajar pada materi pembagian bilangan asli.

\section{METODE PENELITIAN}

Metode penelitian yang digunakan adalah Penelitian Tindakan Kelas (PTK) dengan menggunakan model Kemmis dan Mc. Taggart. Penelitian Tindakan kelas adalah suatu kegiatan penelitian yang dilakukan pada sejumlah subjek siswa yang ditujukan untuk memperbaiki situasi pembelajaran di kelas agar terjadi peningkatan kualitas (Arikunto, 2010).

Penelitian Tindakan Kelas dilaksanakan dalam dua siklus pada semester genap tahun pelajaran 2019/2020 dengan jumlah siswa 24 . Penelitian dilakukan kepada siswa kelas 2 SD Negeri Kedungcaluk 1, Kecamatan Krejengan, Kabupaten Probolinggo. Karena masih dalam situasi pandemi, maka pembelajaran dilakukan dengan cara daring.

Pengumpulan data pada penelitian ini adalah dengan tes dan non tes. Tes hasil belajar dilakukan pada setiap selesai tindakan, sedangkan non tes dilakukan dengan pengamatan, wawancara, dan dokumentasi terhadap kegiatan yang sedang berlangsung. Teknik analisis data ditujukan untuk mengetahui pengaruh penggunaan media realia terhadap peningkatan hasil belajar matematika siswa kelas 2 SD. 


\section{HASIL DAN PEMBAHASAN}

Penelitian sebelumnya, (Hastin, 2016) menyebutkan bahwa media realia memberikan pengaruh terhadap prestasi belajar matematika siswa. (Lathipah, 2018) memaparkan bahwa penggunaan media realia dalam pembeajaran dapat meningkatkan minat belajar siswa. (Habibah \& Wardhani, 2019) menyatakan bahwa media realia merupakan suatu media pembelajaran yang efektif untuk digunakan dalam kegiatan pembelajaran. Tidak hanya itu, media realia juga pernah digunakan dalam penelitian (Ismiyanti, 2015) dengan hasil bahwa melalui media realia, siswa tunagrahita sedang, mampu mengenal warna dengan benar.

Hal yang membedakan penelitian ini dengan penelitian sebelumnya adalah pada subjek, objek, serta metode penelitian yang digunakan. Pada penelitian ini, objek yang diukur adalah peningkatan hasil belajar dan metode penelitian yang digunakan adalah penelitian tindakan kelas.

Media realia pada penelitian ini diterapkan pada materi pembagian bilangan asli dengan menggunakan benda-benda di sekitar seperti sedotan, lego, manik-manik, atau benda apa saja yang dimiliki oleh siswa. Pembelajaran secara daring dilakukan melalui video call. Guru menjelaskan cara menghitung pembagian dengan menggunakan media realia.

Berikut adalah salah satu contoh Langkah-langkah menghitung pembagian bilangan asli dengan menggunakan media realia. Misalkan pada pembagian 12 : 4. Pembagian ini mengandung pengertian bahwa berapa banyak himpunan $\quad 4$ yang menghasilkan 12.

Pengerjaan pembagian dilakukan dengan menyediakan sebuah himpunan bernilai nol. Untuk mendapatkan 12 berarti kita harus menjadikan himpunan yang semula bernilai nol menjadi bernilai Jika menggunakan media realia, artinya harus membuat himpunan tersebut terisi oleh 12 media realia. Selanjutnya, untuk mengetahui berapa banyak himpunan 4 yang menghasilkan 12 , kita dapat menambahkan himpunan

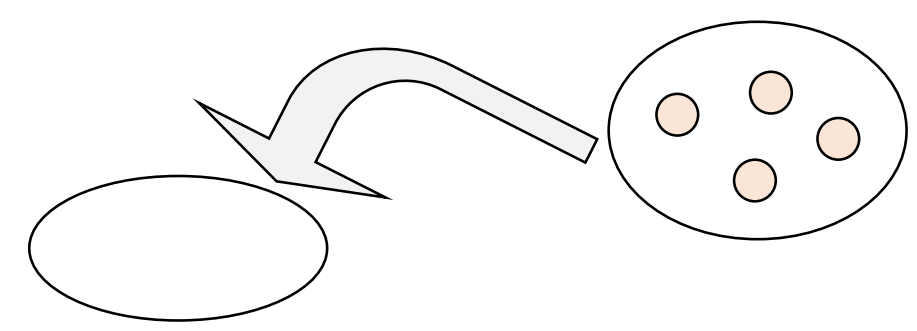

Gambar 1. Ilustrasi Penambahan Himpunan

Prismatika: Jurnal Pendidikan dan Riset Matematika Vol. 3 No. 2 (2021) p-ISSN: 2654-6140, e-ISSN: 2656-4181

http://ejurnal.budiutomomalang.ac.id/index.php/prismatika 
Sekarang di dalam himpunan berisi 4. Karena belum mencapai 12 , kita perlu mengulangi penambahan himpunan berisi 4 lagi.

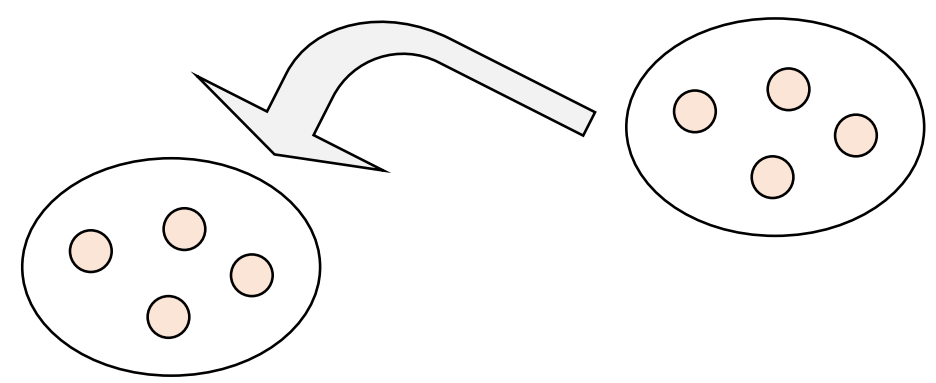

Sekarang di dalam himpunan berisi 8. Karena belum mencapai 12 , kita perlu mengulangi penambahan himpunan berisi 4 lagi.

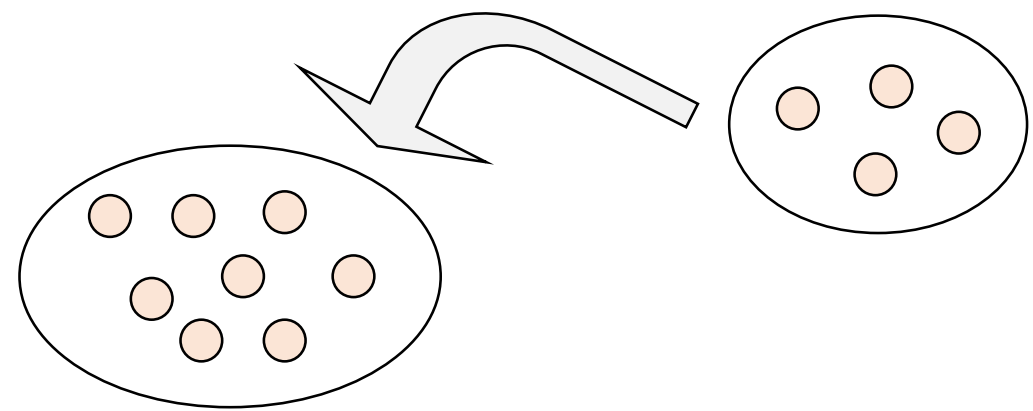

Dengan demikian, pada himpunan telah terisi 12. Dalam proses ini kita telah menambahkan 3 kali himpunan 4 sehingga menghasilkan

12. Jadi, $12: 4=3$

Berdasarkan cara tersebut, siswa akan menggunakan media realia sesuai dengan benda apa yang mereka miliki di rumah untuk kemudian menghitung operasi pembagian pada bilangan yang lain. Hal ini dilakukan berulang hingga siswa memahami konsep pembagian sebenarnya, lalu biarkan ia menemukan pola penghitungan pembagian sendiri sebelum dikenalkan dengan algoritma tradisional yang biasa digunakan untuk menghitung pembagian. Seperti yang diungkap oleh (Hasan, 2017) bahwa pembelajaran pembagian hendaknya disajikan dari bentuk konkret hingga pada bentukm formal.

Melalui hasil tes yang dilakukan setelah tindakan, hasil belajar matematika siswa kelas 2 SD Kedungcaluk 1 Kecamatan Krejengan, Kabupaten Probolinggo diperoleh data seperti pada tabel 1 berikut. 
Tabel 1. Rata-Rata Nilai Tes Hasil Belajar Matematika Siswa

\begin{tabular}{|c|c|c|}
\hline Pra Siklus & Siklus 1 & Siklus 2 \\
\hline 72,53 & 84,21 & 90,65 \\
\hline
\end{tabular}

Berdasarkan data tersebut, dapat dilihat bahwa terdapat peningkatan sebesar $11,68 \%$ dari rata-rata nilai tes pada pra siklus ke siklus 1 , kemudian terdapat kenaikan $6,44 \%$ dari siklus 1 ke siklus 2 . Artinya, ada kenaikan sebesar 18,12\% dari hasil rata-rata nilai tes pra siklus ke siklus 2 .

Hal ini memberikan pengertian bahwa telah ada peningkatan persentase yang signifikan dari hasil belajar matematika siswa pada saat sebelum menggunakan media realia hingga dilangsungkan pembelajaran menggunakan media realia pada siklus 2 dalam penelitian Tindakan kelas.

Berdasarkan hasil wawancara, siswa memaparkan bahwa mereka lebih bersemangat dan antusias dalam mengikuti pembelajaran. Mereka menjadi termotivasi untuk belajar lebih baik lagi. (Muhammad, 2016) Motivasi yang diwujudkan dalam bentuk tindakan adalah suatu faktor untuk memprediksi kemajuan belajar. Siswa yang memiliki motivasi belajar yang tinggi akan melakukan kegiatan belajar yang baik sehingga tujuan pembelajaran dapat dicapai (Emda, 2017).

Berdasarkan pengamatan selama pembelajaran, guru dapat melihat bahwa penggunaan media realia dalam pembelajaran pembagian bilangan asli pada pembelajaran matematika di kelas 2 SD Negeri Kedungcaluk 1 Kecamatan Krejengan Kabupaten Probolinggo dapat dilihat bahwa hasil belajarnya menjadi lebih optimal.

Media realia dapat memudahkan siswa belajar dengan cara menemukan sendiri melalui kegiatan yang menyenangkan. Dengan demikian, kemampuan bernalar siswa akan terlatih sehingga mereka terbiasa secara mandiri untuk memecahkan masalah tanpa bantuan orang lain (Salmi, 2019). Penggunaan media realia juga menjadikan siswa terlibat secara aktif dalam kegiatan pembelajaran. Siswa memiliki pengalaman baru yang berharga. Dengan demikian, rasa ingin tahu dan perhatian siswa dapat difasilitasi. 


\section{KESIMPULAN DAN SARAN}

Peningkatan hasil belajar matematika siswa melalui media realia pada materi pembagian di kelas 2 SD Negeri Kedungcaluk 1 Kecamatan Krejengan Kabupaten Probolinggo dapat dikatakan signifikan kareha terus meningkat dari pra siklus, siklus 1, hingga siklus 2. Artinya, media realia dalam penelitian tindakan kelas ini dapat meningkatkan hasil belajar siswa. Pada penelitian berikutnya, media realia dapat dikembangkan dengan menggunakan objek penelitian serta metode penelitian yang berbeda.

\section{DAFTAR PUSTAKA}

Ardini, P. P., Ibrahim, N., Zubaidi, M., \& Syahputra, H. (2019). Media Realia dalam Mengenalkan Kosakata Anak Kelompok A di TK Kembang Teratai Kelurahan Lekobalo Kecamatan Kota Barat Kota Gorontalo. JPP PAUD FKIP Unitra, 6(1), 63-80.

Arikunto, S. (2010). Prosedur Penelitian Suatu Pendekatan Praktik. Jakarta: Rineka Cipta.

Cipta, D. S. (2019). Penerapan Metode Inkuiri dengan Pendekatan Tanoshi Jugyou untuk Memperbaiki Konsep Operasi Bilangan. Prismatika: Jurnal Pendidikan dan Riset Matematika, 1(2), 60-68. doi:https://doi.org/10.33503/prismatika.v1i2.434

Emda, A. (2017). Kedudukan Motivasi Belajar Siswa dalam Pembelajaran. Lantanida Journal, 5(2), 93-196.

Habibah, U., \& Wardhani, D. A. (2019). Pengaruh Penggunaan Media Realia terhadap Hasil Belajar Siswa pada Pembelajaran Tematik Kelas 1. Elementa: Jurnal PGSD SYKIP Banjarmasin, 1(2), 158-167. doi:10.33654/pgsd

Hasan, Q. A. (2017). Pengembangan Pembelajaran Operasi Pembagian dengan Menekankan Aspek Pemahaman. Jurnal Pendidikan, 18(2), 106-114.

Hastin, M. (2016). Pengaruh Media Realia terhadap Prestasi Belajar Matematika Siswa Kelas X SMK. Jurnal Pelangi, 8(2), 203-209. doi:http://dx.doi.org/10.22202/jp.2016.v8i2.1278

Ismiyanti, F. (2015). Efektifitas Media Realia untuk Meningkatkan Pemahaman Mengenal Warna bagi Anak Tunagrahita Sedang. EJUPEKhu: Jurnal Ilmia Pendidikan Khusus, 1(1), 197-209. Retrieved from http://ejournal.unp.ac.id/index.php/jupekhu

Kamarullah. (2017). Pendidikan Matematika di Sekolah Kita. Al Khawarizmi: Jurnal Pendidikan dan Pembelajaran Matematika, 1(1), 21-32. 
Lathipah, H. (2018). Penggunaan Real Object dapat Meningkatkan Minat Belajar Sains Anak Usia 5 - 6 Tahun. EL BANAR: Jurnal Pendidikan dan Pengajaran, 1(1), 13-20. Retrieved from https://ojs.staibanisaleh.ac.id/index.php/ElBanar/article/view/9

Muhammad, M. (2016). Pengaruh Motivasi dalam Pembelajaran. Lantanida Journal, 4(2), 87-97.

Pratiwi, I. (2019). Efek Program PISA terhadap Kurikulum di Indonesia. Jurnal Pendidikan dan Kebudayaan, 4(1), 51-71. doi:10.24832/jpnk.V4i1.1157

Salmi. (2019). Penerapan Model Pembelajaran Discovery Learning dalam Meningkatkan Hasil Belajar Ekonomi Peserta Didik Kelas XII IPS.2 SMA Negeri 13 Palembang. Jurnal Profit, 6(1), 1-16.

Sari, A. H. (2020, April). Peningkatan Hasil Belajar Matematika melalui Media Realia pada Siswa Kelas 2 SD. Jurnal PG-PAUD Trunojoyo, 7(1), 52-58. doi:10.21107/pgpaudtrunojoyo.v7i1.6835

Sugiharti. (2018). Penggunaan Media Realia (Nyata) untuk Meningkatkan Aktifitas dan Hasil Belajar Matematika Kompetensi Mengenal Lambang Bilangan pada Siswa Kelas 1 SDN 02 Kartoharjo Kota Madiun. Jurnal Edukasi Gemilang, 3(1), 7-14.

Suwardi, Firmiana, M. E., \& Rohayati. (2014). Pengaruh Penggunaan Alat Peraga terhadap Hasil Pembelajaran Matematika pada Anak Usia Dini. Jurnal Al-Azhar Indonesia Seri Humaniora, 2(4), 297-305. 